\title{
MENDAPATKAN WORD OF MOUTH DI SOCIAL MEDIA DAN LOYALITAS DENGAN DIGITAL CUSTOMER EXPERIENCE
}

Submitted Date :

30 April 2020

Accepted Date :

19 Oktober 2020

\author{
Andy Pratama Sulistyo \\ Universitas Airlangga Indonesia \\ andypsulistyo@gmail.com
}

\section{Suggested Citation:}

Roy, S. (2018). Effects of customer experience across service types, customer types and time. Journal of Services Marketing. https://doi.org/10.1108/JSM-11-2016-0406

\begin{abstract}
:
The concept of customer experience is indeed not new in marketing, it should be noted again that today's business concepts are starting to change. The various technologies has made companies and marketers rethinking how to build customer experience in the digital world. Therefore, this study aims to determine the effect of digital customer experience on satisfaction, loyalty, and word of mouth in social media. Two hundred millennial were chosen to be respondents, because this generation group will become a sizable market in the industry in the future. All respondents will be given a questionnaire which will then be processed using SEM-PLS analysis techniques. The results of this study indicate that digital customer experience has an influence on word of mouth on social media both directly and indirectly, digital customer experience has an influence on customer loyalty indirectly and digital customer experience has a direct influence on customers.
\end{abstract}

Keywords: Customer Loyalty, Customer Satisfaction, Digital Customer Experience, Word of Mouth in Social Media.

\section{Abstrak:}

Konsep customer experience memang bukan hal baru dalam ilmu pemasaran, namun perlu dicermati kembali bahwa dewasa ini konsep bisnis mulai berubah, masuknya berbagai macam teknologi membuat perusahaan dan pemasar memikirkan kembali bagaimana membangun customer experience dalam dunia digital. Tujuan dari penelitian ini adalah mengetahui pengaruh digital customer experience terhadap kepuasan, loyalitas dan word of mouth di media sosial pada konsumen dalam generasi millennials. 200 generasi millennials dipilih untuk menjadi responden dalam penelitian ini dikarenakan kelompok generasi inilah yang akan menjadi market yang cukup besar dalam industri di masa depan. Semua responden akan diberi kuesioner yang selanjutnya akan diolah menggunakan teknik analisis SEM-PLS. Hasil analisis dalam penelitian ini menunjukan bahwa digital customer experience memiliki pengaruh terhadap word of mouth di social media baik secara langsung maupun tidak langsung, digital customer experinence memiliki pengaruh terhadap customer loyalty secara tidak langsung dan digital customer experience memiliki pengaruh langsung terhadap customer $s$

Kata kunci: Kepuasan Pelanggan, Loyalitas Pelanggan, Pengalaman Konsumen Digital, Word of Mouth in Social Media.

\section{JEL Classification: M31}




\section{Latar Belakang}

Orientasi perusahaan terhadap pemasaran selalu mengalami perubahan dari zaman ke zaman. Dimulai dari era produk dimana pada masa itu jumlah penawaran produk lebih sedikit dibanding jumlah permintaan konsumen, sehingga kompetisi antar perusahaan masih belum terlihat. Era berikutnya adalah era selling, dengan sedikitnya kompetitor perusahaan berusaha menjual produk sebanyak-banyaknya untuk meningkatkan penjualan dan pada akhirnya berdampak ke profitabilitas perusahaan. Di era saat ini, era dimana perusahaan sudah mulai memikirkan konsumen atau biasa kita sebut sebagai customer centric, era ini muncul karena jumlah penawaran cenderung lebih banyak sehingga mulai terjadi kompetisi antar perusahaan.

Setiap perusahaan berjuang untuk memiliki competitive advantage agar dapat memenangkan persaingan. Beberapa cara yang dilakukan perusahaan adalah mulai menggali apa yang menjadi kebutuhan dan keinginan konsumen, perusahaan mulai menjalin relasi dengan konsumen, perusahaan menawarkan layanan yang melebihi ekspektasi konsumennya serta perusahaan juga berusaha menghadirkan sebuah pengalaman yang akan menjadi momen tak terlupakan bagi konsumen baik sebelum melakukan pembelian, pada saat pembelian, pada saat mengkonsumsi hingga berbagai macam pengalaman disiapkan untuk merawat dan menyenangkan hati konsumen setalah konsumen tersebut mengkonsumsi produk. Pengalaman yang dihadirkan oleh perusahaan inilah dalam ilmu pemasaran biasa dikenal sebagai customer experience.

Menurut Lemon (2016) customer experience saat ini menjadi salah satu buzzword di pemasaran, hal ini dikarenakan dengan customer experience pemasar atau perusahaan mampu dengan kuat memahami konsumen di dalam era perilaku konsumen yang semakin kompleks. Dengan kemampuan memahami konsumen, Bolton (2018) mengatakan perusahaan akan lebih efektif dan efisien dalam melayani konsumen. Schmitt (1999) menyatakan bahwa experience memiliki 5 dimensi, yaitu sense, feel, think, act dan relate. Kelima dimensi ini diberikan kepada konsumen melalui 3 tahap customer jorney, Lemon (2016) menjelaskan lebih lanjut ketiga tahap tersebut adalah prepurchase stage, purchase stage dan post purchase stage. Selanjutnya setiap tahap tersebut memiliki touchpoint yang berbeda-beda yang bisa dialami oleh konsumen, yaitu brand owned, partner owned, customer owned dan social. Sehingga, menjadi sebuah tantangan bagi perusahaan untuk menghadirkan pengalaman yang menarik bagi konsumen yang menfasilitiasi setiap dimensi pada setiap tahap perjalanan konsumen.

Tidak hanya perubahan perilaku konsumen yang semakin kompleks yang dapat berdampak terhadap perusahaan. Perubahan teknologi akhir-akhir ini yang semakin cepat dan canggih juga membawa perubahan model bisnis. Kasali (2017) memberikan contoh bagaimana model bisnis baru dibangun di atas dasar teknologi. Sebagai contoh, Alibaba dan Bukalapak sebagai marketplace online di China dan Indonesia yang memberikan kemudahan dan efisiensi bagi konsumen dalam berbelanja, airbnb yang memberikan value lebih bagi pemilik properti, agar properti yang dimiliki namun tidak dipakai bisa bermanfaat menghasilkan nilai bagi pemiliknya, desknear me, yang memberikan efisiensi dan kemudahan bagi karyawan, pelajar, ataupun pengusaha baru untuk mendapatakan tempat untuk berkerja yang bisa di sewa harian bahkan per jam, Gojek yang hadir di Indonesia membawa gebrakan baru bagi konsumen untuk mengkonsumsi ojek dengan cara baru yang lebih canggih, mudah dan murah, Indonesiax yang mengadirkan pengalaman baru dalam proses belajar, dan masih banyak lagi contoh model bisnis baru yang lahir berkat hadirnya teknologi. Hadirnya teknologi menjadi tantangan baru bagi perusahaan dan ilmu pemasaran untuk beradaptasi dan membuat perubahan khususnya dalam mengemas customer experience. Penelitian ini sejalan dengan Lemon (2016) bahwa tantangan dan peluang yang dihadapi perusahaan saat ini adalah melahirkan customer experience dalam konteks digital.

Saat ini perusahaan sudah mulai memanfaatkan berbagai macam teknolgi seperti artificial intelligence $(A l)$, virtual reality (VR), mobile service, internet of thing dan masih banyak teknologi lainnya. Sebagai contoh, Edelman (2015) menuliskan mengenai bagaimana L'Oreal's Makeup Genius App memanfaatkan teknologi virtual untuk membantu konsumen mencoba berbagai macam warna dari produk kosmetiknya. Bagi konsumen mencoba makeup secara virtual merupakan sebuah pengalaman yang menyenangkan dan mempermudah konsumen. Konsumen bebas memilih dan memadukan warna sesuai dengan keinginannya. Contoh lainnya adalah pada bulan agustus 2018 JD.id yang merupakan salahsatu marketplace online di indonesia membuka gerai offline di Jakarta yaitu JD.ID $X$ yang menawarkan pengalaman belanja berbasis artifical intelligence pertama di Indonesia. Dikutip dari website resminya presiden direktur JD.ID Zhang Li menyatakan, "Kami sangat bangga dengan diluncurkannya JD.ID X, pusat pengalaman berbelanja berbasis Al kami yang pertama di Asia Tenggara dan di Indonesia. Ini merupakan langkah pertama dalam pemanfaatan teknologi kami untuk memperkuat Indonesia dengan sebuah pengalaman berbelanja yang baru." 
Hubungan antara customer experience, customer satisfaction dan customer loyalty dinyatakan oleh Pandey (2018), bahwa online customer experience berdampak terhadap loyalty baik secara langsung maupun melalui satisfaction. Hal ini dapat disimpulkan bahwa meneliti kepuasan dan loyalitas konsumen yang dipengaruhi oleh digital customer experience akan memberikan wawasan baru dalam bidang pemasaran. Selain itu dalam berbagai penelitian ilmiah customer experience selalu dihubungkan dengan pengaruhnya terdahadap word of mouth, maka dalam penelitian ini peneliti juga akan melihat hubungan tersebut namun dengan sudut pandang WOM yang baru yaitu melalui WOM di Social Media.

Penelitian ini akan mengambil objek bisnis kuliner di Surabaya, yang menerapkan teknologi digital dalam memberikan perngalaman bagi konsumennya. Penerapan teknologi digital yang dilakukan terserbut terlihat ketika konsumen hendak melakukan pemesanan produk, konsumen dapat memesan produk melalui aplikasi online baik pada saat berada di lokasi tersebut maupun tidak. Pemesanan produk secara online melalui aplikasi yang dikembangkan oleh pemilik bisnis ini mempermudah dan mempercepat konsumen untuk melakukan pemesanan sehingga pada saat konsumen sudah tiba di lokasi, mereka tidak perlu lagi menunggu produk mereka dibuat, melainkan produk yang dipesan telah tersedia dan siap disajikan. Tidak hanya itu, pernerapan teknologi juga nampak pada sistem pembayaran yang masuk di dalam aplikasi yang dikembangkan oleh pemilik bisnis, pembayaran dapat dilakukan secara digital melalui aplikasi tersebut. Melalui aplikasi tersebut konsumen juga dapat berinteraksi dengan pengelola, untuk memberikan masukan, saran, evaluasi, dan konsumen juga mendapat info-info terbaru seputar bisnis kuliner tersebut.

Responden yang ingin diteliti dalam penelitian ini adalah konsumen dalam Generasi $Y$ atau yang biasa disebut sebagai millennials. Generasi millennials adalah kelompok demografis yang lahir pada tahun 1981-2000. Pemilihan generasi millennials sebagai objek penelitian dikarenakan saat ini menurut data dari salah satu lembaga riset Alvara, $34 \%$ persen penduduk Indonesia adalah generasi millenial, di bawahnya generasi $X$ sebesar $20 \%$ dan baby boomer sebesar $13 \%$. Selain itu saat ini hingga beberapa tahun kedepan generasi millennials masuk pada kelompok usia produktif, yang artinya mereka memiliki pekerjaan dan kemampuan/daya beli. Serta Gen Y juga dikenal sebagai digital native. Peluang inilah yang harus diambil oleh perusahaan mulai mengemas strategi pemasaran untuk Gen $Y$ agar dapat memenangkan persaingan.

Dari uraian di atas, maka penelitian ini bertujuan untuk mengatahui pengaruh digital customer experience terhadap word of mouth in social media, customer satisfaction dan customer loyalty pada generasi millenialls. Pengaruh yang diteliti baik secara langsung dan tidak langsung. Penelitian ini juga diharapkan memberikan kontribusi bagi pengembangan konsep pemasaran khususnya yang berhubugan dengan digital customer experience serta menjadikan referensi strategi bagi perusahaan.

\section{Kajian Literatur}

\section{Digital Customer Experience}

Lemon (2016) menyebutkan bahwa pengembangan teknologi mengubah kepabilitas layanan dan sistem serta mengubah customer experience. Bolton (2018) menambahkan kemampuan organisasi dalam memanfaatkan teknologi digital dapat meningkatkan competitive advantage. Pernyataan tersebut juga sejalan dengan pendapat Klaus (2013) bahwa memahami online customer experience dan bagaimana retailer dapat secara strategis memfasilitasi penerapan online experience adalah kunci untuk competitive advantage dan keberlanjutan profitabilitas.

Dalam penelitian yang dilakukan oleh Rose (2012) mengenai online customer experience, online shopping satisfaction, trust in online shopping berpengaruh terhadap online repuchase intention, Ross membagi online customer experience menjadi 2 bagian yaitu cognitive experiential state (CES) dan Affective Experiential State (AES). Dalam cognitve experiential state diukur melalui interactive speed, telepresence, challenge dan skill, sedangkan untuk affective experiential state diukur melalui ease of use, customization, connectedness, aesthetics dan perceived benefit. Penelitian ini memberikan kesimpulan bahwa kemudahaan dalam mengakses dan menggunakan website adalah poin yang paling penting dalam meningkatan online customer experience.

Penelitian serupa di replikasi oleh Martin (2015) dengan manambahkan variabel perceived risk. Kesimpulan dalam penelitian tersebut menyatakan bahwa e-retailer harus fokus untuk memberikan online retail environment melalui affective experience. 
Pandey (2018) melalui penelitiannya mengenai online customer experience in clothing e-retail, membagi online customer experience menjadi 2 dimensi yaitu pyschological dimension dan functionality dimension. Secara lebih rinci dijelaskan sebagai berikut:

a. Pyschological Dimension

Dimensi psikologi ini merepresentasikan ideologi customer terhadap persepsi sosial dan kumpulan pengalaman yang pernah dialami konsumen. Dimensi psikologis ini diukur melalui; e-distrust, yang merujuk pada ketakutan/khawatira konsumen untuk memberikan data pribadinya pada website; e-negative beliefs, merujuk pada ketakutan/khawatiran konsumen yang pada akhirnya menyerah pada iklan/promo online yang berdampak terhadap pembelian produk yang tidak dibutuhkan; e-self inefficacy, merujuk pada kemampuan konsumen dalam mengoperasikan internet; e-logistic ease, merujuk pada kesalahan pengiriman barang; econvenience, merujuk pada konsumen memilih belanja online karena kenyamanan dan kemudahan yang diberikan dalam pemilihan produk; e-enjoyment, belanja online memberi peluang kepada pelanggan untuk menghindari gangguan fisik dan emosional berbelanja melalui mode offline juga menghasilkan manfaat utilitarian dan hedonis

b. Functionality Dimension

Dalam dimensi fungsional, diukur melalui website interactivity, website informativenss, visual engagement, website navigation dan search ease.

\section{Customer Satisfaction}

Sulistyo (2020) menulis bahwa, kepuasan atau ketidakpuasan terhadap sebuah produk atau fasilitas dipengaruhi oleh ekspektasi tingkat kualitas yang ada dibenak konsumen. Menurut Kotler dan Keller (2016) satisfaction adalah perasaan senang atau kecewa seseorang yang timbul karena membandingkan kinerja yang dipersepsikan produk (atau hasil) terhadap ekspektasi konsumen. customer satisfaction menurut Wilkie (1994, dalam Christian dan Dharmayanti, 2013) yaitu merupakan respon emosional terhadap evaluasi pengalaman mengkonsumsi produk atau jasa. Menurut Wirtz dan Lovelock (2016: 130) customer satisfaction adalah perilaku yang terjadi setelah mengkonsumsi layanan.

\section{Customer Loyalty}

Menurut Kotler dan Keller (2016) Loyalitas atau kesetiaan didefinisikan sebagai komitmen yang dipegang kuat untuk membeli atau berlangganan produk atau jasa tertentu dimasa depan meskipun ada pengaruh situasi dan usaha pemasaran yang berpotensi menyebabkan perubahan perilaku.

Menurut Lee et al. (2011) pengukuran Customer Loyalty melalui empat element yaitu:

a. Re-purchase willing, merupakan kemauan konsumen untuk membeli lagi produk atau jasa dimasa depan.

b. Recommendation willing, merupakan kemauan konsumen untuk merekomendasikan produk atau jasa yang telah dikonsumsi kepada calon konsumen.

c. Tolerance to price adjustment, merupakan kemauan konsumen untuk tetap menggunakan produk atau jasa meskipun terdapat penyesuaian harga, dalam hal ini dimungkinkan harga dari produk atau jasa yang biasa dikonsumsi mengalami kenaikan.

d. Consumption frequency, merupakan kemauan konsumen menggunakan produk dan jasa tidak hanya dalam sekali atau dua kali pemakaian melainkan berkali-kali dengan frekuensi yang sesering mungkin.

Srivastava (2016) membedaka customer loyalty dalam 2 bentuk, yaitu behavioral loyalty, sebagai niat konsumen untuk mengulang pembelian dan sikap dalam aktual pembelian; dan attitudinal loyalty, yaitu identifikasi konsumen terhadap penyedia layanan tertentu dan preferensi dari produk/jasa diluar alternatif.

\section{Word of Mouth in Social Media}

Clow (2018) menulis bahwa word of mouth / buzz marketing menekankan pada penyampaian informasi produk malalui konsumen. Rekomendasi dari teman, anggota keluarga lebih memiliki kredibilitas yang besar di banding iklan. WOM/Buzz Marketing dapat bekerja untuk dua alasan, yang pertama orang lebih percaya terhadap pendapat orang lain dibanding iklan, kedua konsumen suka memberikan pendapat mereka dan membagikan apa yang mereka pikirkan.

Di dalam era saat ini, konsumen menyampaikan pemikiran mereka dan menyatakan pendapat mereka mengenai sebuah produk/jasa yang di konsumsinya melalui platform social media. Platform media sosial memfasilitasi komunikasi peer-to-peer dan mewakili bentuk baru sosialisasi konsumen yang dapat memengaruhi perilaku konsumen (Wang, 2012). 
Platform online seperti Facebook memperluas lingkaran sosial $\backslash$ konsumen dan memberikan pengaruh pada frekuensi dan durasi interaksi (Luo dan Zhong, 2015). Dalam platform ini, para peserta terlibat dalam komunikasi dalam jaringan orang-orang di mana individu sering tidak dikenal satu sama lain, dan mereka mempertahankan hubungan mereka melalui saluran ini (King, et al., 2014).

Konsep tradisional word of mouth atau biasa disingkat WOM telah berubah menjadi electronic word of mouth atau biasa disingkat Ewom di era digital ini. Serra-Cantallops, et al. (2018) menulis perbedaaan WOM dan eWOM terletak pada perolehan dampak review (jumlah orang yang terpengaruh) dan kecepatan interaksi. Luasnya lingkup eWOM dan kemudahan dalam mengakses ulasan dapat sangat memengaruhi kinerja perusahaan. Oleh karena itu, perusahaan semakin berusaha untuk memahami faktor-faktor yang mempengaruhi penggunaan eWOM, serta dampak yang dihasilkan dari penggunaannya.

\section{Model Penelitian}

Gambar 1. Model Penelitian

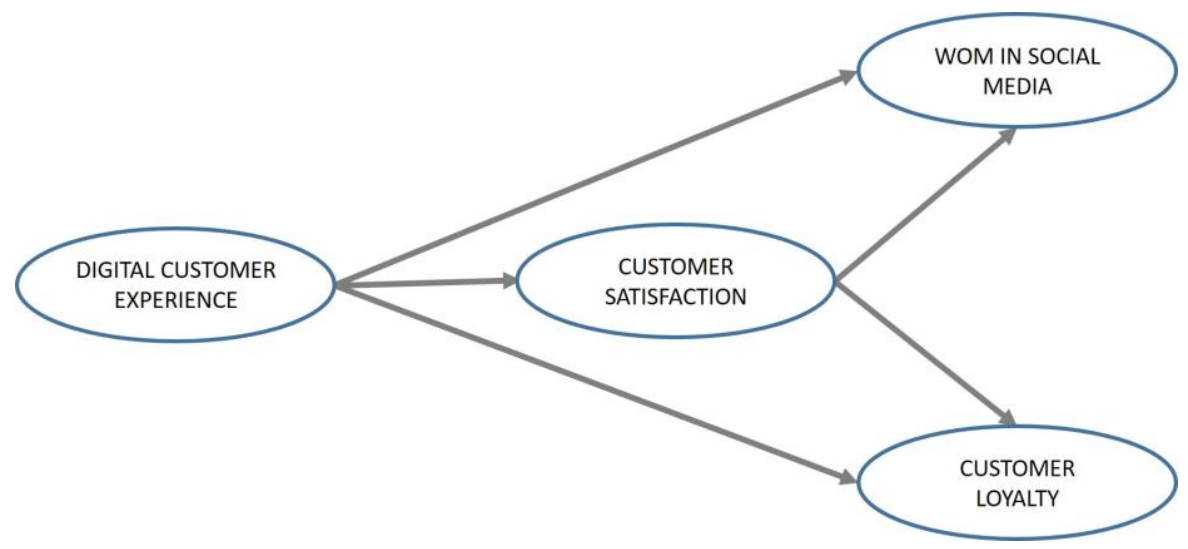

Sumber: Data diolah (2020)

\section{Pengaruh Digital Customer Experience dan WOM in Social Media}

Serra-Cantallops, et al. (2018) dalam penelitiannya mengukapkan bahwa emotional experience memiliki hubungan yang kuat dan sangat positif terhadap eWOM. Sehingga emotional experience menjadi penentu yang kuat dalam menghasilkan behavioral intentioan yaitu eWOM. Berdasarkan penjelasan diatas, maka hipotesis yang dibangun dalam penelitian ini adalah

H1. Digital customer experience memiliki pengaruh terhadap WOM in social media pada konsumen generasi millenial.

\section{Pengaruh Digital Customer Experience dan Customer Loyalty}

Bustamante (2017) dalam penelitiannya menyatakan bahwa customer experience menjadi motivator yang kuat untuk merawat customer relationship dengan toko, dan hal tersebut berdampak langsung terhadap customer loyalty. Srivastava (2016) dalam penelitiannya mengungkapkan customer experience yang baik secara jangka panjang berdampak terhadap performa ritel melalui loyalitas. Selain itu terungkap pula, customer experience mengarah pada attitudinal loyalty dan behavioral loyalty yang mana akan membawa pada peningkatan pembelanjaan pada ritel. Pandey (2018) secara khusus menggaris bawahi bahwa visual engagement dalam online customer experience memiliki pengaruh terhadap loyalitas khususnya untuk wanita. Berdasarkan penjelasan diatas, maka hipotesis yang dibangun dalam penelitian ini adalah

\section{H2. Digital customer experience memiliki pengaruh Customer Loyalty pada konsumen generasi} millennial. 


\section{Customer satifaction sebagai mediasi pengaruh antara digital customer experience, WOM in social media dan Customer Loyalty}

Martin (2015) dalam penelitiannya mengungkapkan bahwa hubungan cognitive experience dengan satisfaction hanya signifikan pada infrequent online shopper. Selain itu kegiatan membangun kepuasan terhadap situs website, terutama yang memengaruhi keadaan pengalaman afektif seperti kemudahan yang dapat digunakan pembeli untuk menggunakan situs, dapat menyesuaikannya untuk kebutuhan mereka dan memperjelas manfaat berbelanja secara online melalui situs website. Hasil penelitian Bustamante (2017) mengenai pengaruh customer experience terhadap satisfaction menyebutkan bahwa, satisfaction menunjukan hubungan yang kuat, positif dan signifikan terhadap customer experience. Pandey (2018) dalam penelitiannya menghasilkan pengaruh online customer experience berdampak terhadap kepuasan khusunya konsumen pria. Hal ini terjadi karena di India jumlah konsumen pria lebih terbiasa berbelanja secara online. Indikator e-negative beliefs dalam online customer experience memiliki dampak yang negatif terhadap kepuasan konsumen pria, akan tetapi indikator visual engagement merupakan faktor yang penting yang bisa berdampak terhadap kepuasan baik untuk pria dan wanita. Serra-Cantallops, et al. (2018) dalam penelitiannya menghasilkan bahwa customer satisfaction memiliki dampak yang kuat terhadap customer loyalty. Ali, et al. (2018) juga menyatakan bahwa satisfaction memiliki pengaruhi customer loyalty dalam konteks customer experience. Dari penjelasan diatas, maka hipotesis yang dibangun dalam penelitian ini adalah.

H3. Digital customer experience memiliki pengaruh terhadap WOM in social media melalui Customer Satisfaction pada konsumen generasi millenial

H4. Digital customer experience memiliki pengaruh terhadap Customer Loyalty melalui Customer Satisfaction pada konsumen generasi millennial

\section{Metode Penelitian}

Jenis data yang digunakan dalam penelitian ini adalah data primer yang didapatkan melalui survey. Populasi dalam penelitian ini adalah konsumen pada kelompok usia generasi millenials yaitu usia 18-37 di tahun 2018 yang pernah melakukan pembelian di Café XYZ yang berlokasi di Surabaya. Sugiyono (2010) menyatakan ukuran sampel yang layak dalam penelitian adalah antara $30-500$. Sehingga dalam penelitian ini ditentukan sebanyak 200 sampel

Teknik pengambilan sampel dalam penelitian ini menggunakan nonprobability sampling dengan metode judgmental sampling. Untuk memutuskan populasi yang diikutsertakan menjadi sampel dalam penelitian ini maka, karakteristik responden yang dibutuhkan adalah sebagai berikut: Berusia 18 tahun - 37 tahun, pernah melakukan pembelian di cafe XYZ, menggunakan teknologi digital yang disediakan oleh cafe $\mathrm{XYZ}$, memiliki akun social media, memberikan komentar di media sosial. minimal 1 bulan sekali, menggugah foto/video di media sosial minimal 1 bulan sekali.

Metode yang digunakan dalam pengumpulan data dalam penelitian ini adalah melalui survey. Sampel/responden dalam penelitian ini akan menerima kuesioner dengan isian skala likert bernilai 1-5. Kemudian hasil dari kuesioner diolah dengan teknik analisis Structural Equation Modeling (SEM) PLS. Dipilihnya SEM PLS karena jumlah sample yang kecil dalam penelitian ini. PLS mampu digunakan pada sample kecil dibandingan aplikasi SEM yang lain seperti AMOS, dan Lisrel.

Hasil

Secara umum responden penelitian ini diidentifikasikan berdasarkan beberapa elemen, yaitu usia, domisili, pekerjaan dan frekuensi kunjungan ke cafe. Dalam penelitian ini, kuesioner disebar sebanyak 200 kuesioner dengan profil responden sebagai berikut:

Tabel 1. Profil Responden

\begin{tabular}{|l|l|c|c|}
\hline \multirow{2}{*}{$\begin{array}{l}\text { Jenis } \\
\text { Kelamin }\end{array}$} & Profil & Jumlah & Prosentase \\
\cline { 2 - 4 } & Wanita & 101 & 50,5 \\
\hline \multirow{2}{*}{ Domisili } & Surabaya & 99 & 49,5 \\
\cline { 2 - 4 } & Luar Surabaya & 107 & 53,5 \\
\hline \multirow{3}{*}{ Pekerjaan } & Mahasiswa & 93 & 46,5 \\
\cline { 2 - 4 } & Karyawan Swasta & 77 & 38,5 \\
\cline { 2 - 4 } & PNS & 36 & 18 \\
\hline
\end{tabular}




\begin{tabular}{|c|c|c|c|}
\hline \multicolumn{2}{|r|}{ Profil } & Jumlah & Prosentase \\
\hline & Lain-lain & 73 & 46,5 \\
\hline \multirow{5}{*}{$\begin{array}{l}\text { Frekuensi } \\
\text { kunjungan ke café } \\
\text { per bulan }\end{array}$} & $1 \mathrm{x}$ & 24 & 12 \\
\hline & $2 x$ & 29 & 14,5 \\
\hline & $3 x$ & 71 & 35,5 \\
\hline & $4 x$ & 39 & 19,5 \\
\hline & Lebih dari $4 \mathrm{x}$ & 37 & 18,5 \\
\hline \multirow{5}{*}{$\begin{array}{l}\text { Frekuensi } \\
\text { berkomentar di } \\
\text { media sosial per } \\
\text { bulan }\end{array}$} & 1-10 kali & 72 & 36 \\
\hline & $11-20$ kali & 49 & 24,5 \\
\hline & $21-30$ kali & 51 & 25,5 \\
\hline & $31-40$ kali & 15 & 7,5 \\
\hline & Lebih dari 40 kali & 13 & 6,5 \\
\hline \multirow{5}{*}{$\begin{array}{l}\text { Frekuensi posting } \\
\text { di media sosial } \\
\text { per bulan }\end{array}$} & $1-5$ kali & 73 & 36,5 \\
\hline & $6-10$ kali & 73 & 36,5 \\
\hline & $11-15$ kali & 34 & 17 \\
\hline & $16-20$ kali & 13 & 6,5 \\
\hline & Lebih dari 21 kali & 7 & 3,5 \\
\hline
\end{tabular}

Sumber: data diolah

\section{Uji Validitas dan Reliabilitas}

Hair dkk., (2019: 775-776) menyatakan rule of thumb yang digunakan dalam pengujian validitas dilihat dari nilai factor loading yang $>0,70$ dan nilai average variance extracted $>0,50$. Berdasarkan aturan tersebut semua indikator yang digunakan dalam pengujian ini telah terbukti valid karena nilai faktor loading untuk masing-masing konstruk lebih dari 0,7 dan nilai average variance extracted (AVE) lebih dari 0,5. Uji reliabilitas dalam SEM-PLS dilihat dengan menggunakan dua metode yaitu, cronbach's alpha dan composite reability. Hair dkk., (2019: 775776) menuliskan nilai minimum yang harus dicapai oleh kedua metode tersebut adalah 0,7. Berdasarkan pengujian, didapati bahwa nilai cronbach's alpha untuk variabel digital customer experience adalah 0,870 , WOM in social media adalah 0,874 , customer sastisfaction adalah 0,855 dan customer loyalty adalah 0,782 . Nilai composite reliability dari variabel digital customer experience adalah 0,911, WOM in social media adalah 0,914, customer sastisfaction adalah 0,861 dan customer loyalty adalah 0,897. Berdasarkan hasil pengujian tersebut dapat disimpulkan bahwa variabel yang digunakan dalam penelitian ini reliabel.

\section{Pengujian Model Struktural}

Berdasarkan hasil uji hipotesis yang telah dilakukan dengan metode analisis SEM, maka didapati hasil sebagai berikut :

Tabel 2. Uji Model Struktural

\begin{tabular}{|l|c|c|c|}
\hline \multicolumn{1}{|c|}{ Hipotesis } & T-Statistic & P-Value & Keterangan \\
\hline H1. Digital customer experience $\rightarrow$ WOM in social media & 6,359 & 0,000 & Diterima \\
\hline H2. Digital customer experience $\rightarrow$ customer loyalty & 1,736 & 0,083 & Ditolak \\
\hline $\begin{array}{l}\text { H3. Digital customer experience } \rightarrow \text { customer satisfaction } \rightarrow \text { WOM in social } \\
\text { media }\end{array}$ & 35,732 & 0,000 & Diterima \\
\hline H4. Digital customer experience $\rightarrow$ customer satisfaction $\rightarrow$ customer loyalty & 8,454 & 0,000 & Diterima \\
\hline
\end{tabular}

Sumber: data diolah

Dari tabel di atas dapat disimpulkan bahwa hipotesis satu $(\mathrm{H} 1)$ yaitu digital customer experience memiliki pengaruh terhadap WOM in social media pada konsumen generasi millenial di café XYZ karena memiliki nilai tstatistik sebesar 6,539 dan nilai $p$-value 0,000 yang lebih kecil dari nilai alpha 0,5 sehingga $\mathrm{H} 1$ dinyatakan diterima. Hipotesis dua $(\mathrm{H} 2)$ yaitu digital customer experience memiliki pengaruh customer loyalty pada konsumen generasi millenials di café XYZ karena memiliki nilai t-statistik sebesar 1,736 yang lebih kecil dari 1,96 dan nilai $p$-value 0,083 yang lebih besar dari nilai alpha 0,5 sehingga $\mathrm{H} 2$ dinyatakan ditolak. Hipotesis 3 yaitu digital customer experience memiliki pengaruh terhadap WOM in social media melalui customer satisfaction pada konsumen generasi millenial di café XYZ karena memiliki nilai t-statistik sebesar 35,732 dan nilai $p$-value 0,000 
yang lebih kecil dari nilai alpha 0,5 sehingga $\mathrm{H} 3$ dinyatakan diterima. Hipotesis empat yaitu digital customer experience memiliki pengaruh terhadap customer loyalty melalui customer satisfaction pada konsumen generasi millenial di café XYZ karena memiliki nilai t-statistik sebesar 8,454 dan nilai $p$-value 0,000 yang lebih kecil dari nilai alpha 0,5 sehingga $\mathrm{H} 4$ dinyatakan diterima.

Tabel 3. Uji Efek Tidak Langsung

\begin{tabular}{|l|c|c|c|}
\hline \multicolumn{1}{|c|}{ Hipotesis } & T-Statistic & P-Value & Keterangan \\
\hline $\begin{array}{l}\text { Digital customer experience } \rightarrow \text { Customer } \\
\text { Satisfaction }\end{array}$ & 14,754 & 0,000 & $\begin{array}{c}\text { Memiliki pengaruh tidak } \\
\text { langsung }\end{array}$ \\
\hline Customer satisfaction $\rightarrow$ WOM in social media & 7,807 & 0,000 & $\begin{array}{c}\text { Memiliki pengaruh tidak } \\
\text { langsung }\end{array}$ \\
\hline Customer satisfaction $\rightarrow$ customer loyalty & 14,143 & 0,000 & $\begin{array}{c}\text { Memiliki pengaruh tidak } \\
\text { langsung }\end{array}$ \\
\hline
\end{tabular}

Sumber: data diolah

Dalam pengujian ini juga didapat variabel yang memiliki perngaruh tidak langsung. Variabel digital customer experience memiliki pengaruh tidak langsung terhadap variabel customer satisfaction. Variabel customer satisfaction juga memiliki pengaruh tidak lansgung terhadap variabel WOM in social media dan customer loyalty.

\section{Pembahasan}

\section{Pengaruh digital customer experience dan WOM in social media, serta peran mediasi customer satisfaction}

Pengaruh positif pada digital customer experience pada WOM in social media sejalan dengan Serra-Cantallops, et al. (2018) bahwa experience memiliki hubungan yang kuat dan sangat positif terhadap eWOM. Hal ini berarti ketika perusahaan mampu mengelola digital customer experience maka konsumen akan dengan senang hati memberikan komentar yang positif di media sosial, menggungah foto/video di media sosial tentang pengalamannya selama mengkonsumsi produk, dan menjadi pengikut di akun media sosial perusahaan. Pengaruh positif yang antara digital customer experience terhadap WOM in social media, juga di mediasi oleh variabel customer satisfaction.

\section{Pengaruh digital customer experience dan customer loyalty, serta peran mediasi customer satisfaction}

Pengaruh antara digital customer experience terhadap customer loyalty hanya bisa berpengaruh signifikan bila melalui customer satisfaction. Hal ini sejalan dengan hasil penelitian Serra-Cantallops, et al. (2018) bahwa customer satisfaction memiliki dampak yang kuat terhadap customer loyalty. Ali, et al. (2016) juga menyatakan bahwa satisfaction memiliki pengaruhi customer loyalty dalam konteks customer experience. Pandey dan Chawla (2018) dalam penelitiannya juga menujukan bahwa beberapa variabel experience seperti e-distrust, e-negative beliefs, e-self inefficacy dan e-enjoyment tidak memiliki pengaruh terhadap loyalty secara langsung. Sehingga dapat disimpulkan bahwa, apabila perusahaan ingin menghasilkan customer loyalty, maka perusahaan harus mampu membuat customer puas terlebih dahulu.

\section{Kesimpulan}

Berdasarkan hasil analisis dan pembahasan yang telah diuraikan sebelumnya, maka dapat diambil kesimpulan bahwa Digital customer experience berpengaruh terhadap WOM in social media, digital customer experience tidak berpengaruh terhadap customer loyalty pada generasi millenials. Digital customer experience tidak berpengaruh terhadap WOM in social media melalui customer satisfaction pada generasi millenials. Digital customer experience tidak berpengaruh terhadap customer loyalty melalui customer satisfaction pada generasi millenials.

Berapa saran yang bisa diterapkan berdasarkan hasil penelitian ini adalah penerapan digital customer experience di Café XYZ telah menujukan bahwa strategi tersebut tepat dan mampu menghasilkan WOM in social media, kepuasaan dan loyalitas konsumen. Sehingga penerapan strategi ini untuk kedepan perlu ditingkatkan lagi sehingga konsumen semakin puas dan loyal terhadap Café XYZ khususnya bagi generasi Millenials. Membuat konsumen merasa loyal terhadap Café XYZ tidak bisa didapat langsung melalui penerepan digital 
customer experience, Café XYZ harus terlebih dahulu membuat konsumen merasa puas. Kembali kepada definisi operasional kepuasaan dalam penelitian ini, konsumen merasa puas bila keputusan pembelian di Café $\mathrm{XYZ}$ bagi konsumen dirasa benar dan tepat. Penelitian ini juga ingin berkontribusi terhadap teori pemasaran, khususnya mengenai digital customer experience. Dari hasil dan pembahasan di atas maka dapat diambil kesimpulan bahwa, digital customer experience dapat memberikan pengaruh kepada WOM in social media, customer satisfaction dan berpengaruh tidak langsung kepada customer loyalty pada generasi millenials.

\section{Daftar Pustaka}

Ali, F., Kim, W. G., Li, J., \& Jeon, H. M. (2018). Make it delightful: Customers' experience, satisfaction and loyalty in Malaysian theme parks. Journal of Destination Marketing and Management. https://doi.org/10.1016/j.jdmm.2016.05.003

Bolton, R. N., McColl-Kennedy, J. R., Cheung, L., Gallan, A., Orsingher, C., Witell, L., \& Zaki, M. (2018). Customer experience challenges: bringing together digital, physical and social realms. Journal of Service Management, 29(5), 776-808. https://doi.org/10.1108/JOSM-04-2018-0113

Bustamante, J. C., \& Rubio, N. (2017). Measuring customer experience in physical retail environments. Journal of Service Management. https://doi.org/10.1108/JOSM-06-2016-0142

Christian, A., \& Dharmayanti, D. (2013). Pengaruh Experiential Marketing Terhadap Customer Satisfaction Dan Customer Loyalty the Light Cup Di Surabaya Town Square. Jurnal Manajemen Pemasaran Petra.

Clow, K. E., \& Baack, D. (2018). Integrated Advertising, Promotion, and Marketing Communication (8th ed.). London: Pearson Education Limited.

Edelman, D. C., \& Singer, M. (2015). Competing on customer journeys. Harvard Business Review.

Hair Jr, J. F., Black, W. C., Babin, B. J., \& Anderson, R. E. (2019). Multivariate Data Analysis (8th ed.). Hampshire: Cengage Learning.

Kasali, R. (2017). Disruption. Jakarta: PT. Gramedia Pustaka Utama.

King, R. A., Racherla, P., \& Bush, V. D. (2014). What we know and don't know about online word-of-mouth: A review and synthesis of the literature. Journal of Interactive Marketing. https://doi.org/10.1016/j.intmar.2014.02.001

Klaus, P., \& Maklan, S. (2013). Towards a better measure of customer experience. International Journal of Market Research. https://doi.org/10.2501//JMR-2013-021

Kotler, P., \& Keller, K. K. (2016). Marketing Management (15th ed.). Pearson.

Lee, M.-S., Hsiao, H.-D., \& Yang, M.-F. (2010). The study of the relationships among experiential marketing, service quality, customer satisfaction and customer loyalty. The International Journal of Organizational Innovation, 3(2), 353-379.

Lemon, K. N., \& Verhoef, P. C. (2016). Understanding Customer Experience Throughout the Customer Journey. Journal of Marketing, 80(6), 69-96. https://doi.org/10.1509/jm.15.0420

Lovelock, C. H., \& Wirtz, J. (2016). Services Marketing: People, Technology, Strategy No Title (8th ed.). New York: World Scientific Publishing Co. Inc.

Luo, Q., \& Zhong, D. (2015). Using social network analysis to explain communication characteristics of travelrelated electronic word-of-mouth on social networking sites. Tourism Management. https://doi.org/10.1016/j.tourman.2014.07.007 
Martin, J., Mortimer, G., \& Andrews, L. (2015). Re-examining online customer experience to include purchase frequency and perceived risk. Journal of Retailing and Consumer Services. https://doi.org/10.1016/j.jretconser.2015.03.008

Pandey, S., \& Chawla, D. (2018). Online customer experience (OCE) in clothing e-retail. International Journal of Retail \& Distribution Management. https://doi.org/10.1108/ijrdm-01-2017-0005

Rose, S., Clark, M., Samouel, P., \& Hair, N. (2012). Online Customer Experience in e-Retailing: An empirical model of Antecedents and Outcomes. Journal of Retailing, 88(2), 308-322. https://doi.org/10.1016/j.jretai.2012.03.001

Schmitt, B. (2011). Experience Marketing: Concepts, Frameworks and Consumer Insights. Foundations and Trends® in Marketing, 5(2), 55-112. https://doi.org/10.1561/1700000027

Serra-Cantallops, A., Ramon-Cardona, J., \& Salvi, F. (2018). The impact of positive emotional experiences on eWOM generation and loyalty. Spanish Journal of Marketing - ESIC. https://doi.org/10.1108/SJME-032018-0009

Srivastava, M., \& Kaul, D. (2016). Exploring the link between customer experience-loyalty-consumer spend. Journal of Retailing and Consumer Services. https://doi.org/10.1016/j.jretconser.2016.04.009

Sugiyono. (2010). Metode Penelitian Bisnis. Bandung: Alfabeta.

Sulistyo, A. P. (2020). Delivering Experiential Markerting and Service Quality to Improve Customer Loyalty in Public Transportation. International Journal of Trend in Scientific Research and Development, 4(4), 351355.

Wang, X., Yu, C., \& Wei, Y. (2012). Social Media Peer Communication and Impacts on Purchase Intentions: A Consumer Socialization Framework. Journal of Interactive Marketing. https://doi.org/10.1016/j.intmar.2011.11.004

jd-id-hadirkan-jd-id-x-pusat-pengalaman-berbelanja-berbasis-artificial-intelligence-ai-pertama-di-indonesia_219 @ www.jd.id. (n.d.). Retrieved from https://www.jd.id/blog/jd-id-hadirkan-jd-id-x-pusat-pengalamanberbelanja-berbasis-artificial-intelligence-ai-pertama-di-indonesia_219.html (diakses tanggal 28 januari 2020) 